\title{
Interpretation of observed microwave signatures from ground dual polarization radar and space multi-frequency radiometer for the 2011 Grímsvötn volcanic eruption
}

\author{
M. Montopoli ${ }^{1,4,5}$, G. Vulpiani ${ }^{2}$, D. Cimini ${ }^{3,5}$, E. Picciotti ${ }^{5,6}$, and F. S. Marzano ${ }^{4,5}$ \\ ${ }^{1}$ Department of Geography, University of Cambridge, Cambridge, UK \\ ${ }^{2}$ Department of Civil Protection, Rome, Italy \\ ${ }^{3}$ IMAA-CNR, Tito scalo, Potenza, Italy \\ ${ }^{4}$ Dep. of Information Engineering, Electronics and Telecommunications, Sapienza University of Rome, Rome, Italy \\ ${ }^{5}$ CETEMPS, University of L'Aquila, L'Aquila, Italy \\ ${ }^{6}$ Himet srl, L'Aquila, Italy \\ Correspondence to: M. Montopoli (mario.montopoli@gmail.com)
}

Received: 9 May 2013 - Published in Atmos. Meas. Tech. Discuss.: 9 July 2013

Revised: 7 January 2014 - Accepted: 8 January 2014 - Published: 19 February 2014

\begin{abstract}
The important role played by ground-based microwave weather radars for the monitoring of volcanic ash clouds has been recently demonstrated. The potential of microwaves from satellite passive and ground-based active sensors to estimate near-source volcanic ash cloud parameters has been also proposed, though with little investigation of their synergy and the role of the radar polarimetry. The goal of this work is to show the potentiality and drawbacks of the X-band dual polarization (DPX) radar measurements through the data acquired during the latest Grímsvötn volcanic eruptions that took place in May 2011 in Iceland. The analysis is enriched by the comparison between DPX data and the observations from the satellite Special Sensor Microwave Imager/Sounder (SSMIS) and a C-band single polarization (SPC) radar. SPC, DPX, and SSMIS instruments cover a large range of the microwave spectrum, operating respectively at $5.4,3.2$, and $0.16-1.6 \mathrm{~cm}$ wavelengths.

The multi-source comparison is made in terms of total columnar concentration (TCC). The latter is estimated from radar observables using the "volcanic ash radar retrieval" algorithm for dual-polarization X-band and single polarization C-band systems (VARR-PX and VARR-SC, respectively) and from SSMIS brightness temperature (BT) using a linear BT-TCC relationship. The BT-TCC relationship has been compared with the analogous relation derived from SSMIS and SPC radar data for the same case study. Differences
\end{abstract}

between these two linear regression curves are mainly attributed to an incomplete observation of the vertical extension of the ash cloud, a coarser spatial resolution and a more pronounced non-uniform beam-filling effect of SPC measurements ( $260 \mathrm{~km}$ away from the volcanic vent) with respect to the DPX (70 km from the volcanic vent). Results show that high-spatial-resolution DPX radar data identify an evident volcanic plume signature, even though the interpretation of the polarimetric variables and the related retrievals is not always straightforward, likely due to the possible formation of ash and ice particle aggregates and the radar signal impairments like depolarization or non-uniform beam filling that might be caused by turbulence effects. The correlation of the estimated TCCs derived from DPX or SPC and SSMIS BTs reaches approximately -0.7 .

\section{Introduction}

The ability to recognize the signature of volcanic ash clouds on remote sensing data, and therefore to retrieve quantitatively their physical parameters, is of significant importance. The volcanic ash dispersed in the atmosphere after an eruption may have an impact on the environmental, climatic, and socio-economic effects (Cadle et al., 1979). Regular monitoring of volcanic emissions can provide information on the 
underlying volcanic processes, and it can serve as an input source for modelling trajectories of airborne ash (Sparks, 2003). Many recent research efforts have been focusing on the characterization of volcanic plumes and their dynamics into the atmosphere as for example those of Herzog and Graf (2010) and Denlinger et al. (2013).

Investigating the ash dispersion in the atmosphere from remote also offers the practical advantage of monitoring it in near-real-time, thus avoiding impractical or even dangerous conditions of in situ sampling. In this perspective, remote sensing observations provided by visible, infrared, and microwave remote sensors on either ground or satellite platforms are of particular interest. When the observation is close to the volcano vent, remote sensing instruments can be used to estimate the near-source eruption parameters. The most important near-source parameters are the plume height and the tephra eruption rate and mass (Mastin et al., 2009; Marzano et al., 2011; Vulpiani et al., 2011; Maki et al., 2012). The retrieval of these parameters represents an important input for Lagrangian ash dispersion models, which are used to predict the geographical areas likely to be affected by significant levels of ash concentrations (Webley and Mastin, 2009).

Sensors from geostationary earth orbit (GEO) platforms are exploited for long-range trajectory tracking and for measuring eruptions with low ash content (Rose et al., 2000). GEO imagery is available every $15-30 \mathrm{~min}$ at $3-5 \mathrm{~km}$ spatial resolution. When GEO radiometric measurements at visibleinfrared wavelengths are used, water and ice clouds above the ash plume may partially block the sensor field of view, thus making the observations less useful for ash tracking. This feature becomes problematic especially at night, when the lack of visible observations does not allow for ash/water cloud discrimination.

Compared to GEO, sensors in low earth orbits (LEOs) have a longer revisit time (more than $12 \mathrm{~h}$ ) but enhanced spatial resolutions, which vary from several kilometres down to metres, depending upon the sensor and wavelength used (e.g. Grody and Basist, 1996; Marzano et al., 2013a). As a general rule, the smaller the sensor's wavelength is, the higher the horizontal spatial resolution.

Ground-based instruments usually have spatial and temporal resolutions higher than GEO-LEO sensors, though their areal coverage may reach few hundreds of kilometres at most.

Either from ground or space, remote sensors operating at infrared and visible wavelengths suffer from strong ash cloud opacity (mixed with water cloud at times) due to the significant radiation extinction, which is often the case in the proximity of the volcanic source. In this respect, the exploitation of passive microwave sensors represents a good opportunity to probe ash clouds, despite some inherent limitations (Delene et al., 1996; Grody and Basist, 1996; Marzano et al., 2012b; Montopoli et al., 2013).
On the other hand, active microwave sensors have the capability to resolve the scene radially, thus giving the opportunity to obtain three-dimensional pictures of volcanic plumes. Weather radars are an example of such sensors whose use is increasing as an additional tool for volcanic cloud monitoring and quantitative retrieval of ash. A comprehensive overview of recent progress in radar volcanology is given by Marzano et al. (2013b). That paper summarize the basis fundamentals of the radar-driven remote sensing of explosive volcanic eruptions, showing how quantitative estimates of ash category and concentration can be nowadays accomplished with a fairly good degree of confidence within the spatial coverage of weather radars. The interactions between microwaves and ash particles have been described using both experimental and modelling achievements of past studies. These achievements were aimed at characterizing ash particles in terms of their shape, composition, density and particle size distribution, and they have led to a physically based retrieval scheme called volcanic ash radar retrieval (VARR). To support the potentials of VARR, Marzano et al. (2013b) analysed five case studies observed by weather radars at S, C and X frequency bands from various eruptions all over the world. These are the eruptions that occurred in November 2004 in Iceland from the Grímsvötn volcano, in January 2006 in Alaska from the Augustine volcano, in April 2010 in Iceland from the Eyjafjöll volcano, in April 2011 in Italy from the Etna volcano, and finally in May 2011 again from the Grímsvötn volcano. All the aforementioned eruptive case studies provide examples of weather radar signatures at different frequency bands and radar-derived ash products. However, Marzano et al. (2013b) give an overview of the ashrelated radar products without going into detail of radar data processing. Additionally, four out of the five volcanic eruption events were discussed in terms of the single polarization radar data. One case study (Etna volcano) discussed the potential of the polarization diversity for discriminating between spherical and oblate and/or prolate ash particle, and its implication to the derived product of ash concentration.

This work adds original elements on the interpretation of the dual polarization radar signal when an explosive volcanic eruption is observed. Passive microwave observations from satellite, collocated with the ground radar acquisition, are also used to investigate the role of ash products from ground-based radars in helping calibration procedures of satellite microwave sensors. With this aim, available measurements collected during the Grímsvötn eruption in Iceland on 22 May 2011 are used. Note that the Grímsvötn eruption considered in this work and observed by the X-band dual polarization radar is a Plinian style event, and it was classified as class 4 at least within a range $0-8$ in terms of volcanic explosive index (Newhall and Self 1982). On the contrary, the Etna event, considered in the introductory paper by Marzano et al. (2013b) and observed by the same radar system used in this work, is a Strombolian style eruption that typically implies a VEI less than 3. 
Table 1. Technical specifications of the DPX radar used for the analysed case study during Grímsvötn 2011.

\begin{tabular}{ll}
\hline Parameter & Value \\
\hline Radar type & $\begin{array}{l}\text { X-band meteor 50DX } \\
(9.4 \mathrm{GHz})\end{array}$ \\
\hline Transmitter peak power & $75 \mathrm{~kW}$ \\
Pulse duration & $1.33 \mu \mathrm{s}$ \\
Pulse repetition frequency (PRF) & $550 \mathrm{~Hz}$ \\
Minimum detectable signal & $-113 \mathrm{dBm}$ \\
Sampled pulses & 23 \\
Antenna type & Parabolic, prime focus \\
& reflector \\
Minimum antenna gain & $42.5 \mathrm{~dB}$ \\
Half power beam width & $1.3 \mathrm{deg}$ \\
Reflector diameter & $1.8 \mathrm{~m}$ \\
Duration of 360 deg scan & $20 \mathrm{~s}$ \\
Duration of antenna elevation rising & $5 \mathrm{~s}$ \\
\hline
\end{tabular}

Retrievals of mass loading from space observations obtained from the LEO passive Special Sensor Microwave Imager/Sounder (SSMIS) are compared with those derived using ground-based radars. Radar data are provided by the X-band dual polarization radar (DPX), operated in Iceland during 2011 on loan from the Italian Department of Civil Protection to the Iceland Meteorological Office. SSMIS acquisitions are obtained from the US Defense Meteorological Satellite Program (DMSP) F-17 satellite. Data from the single-polarization radar at C-band (SPC), operated at the Keflavik airport in Iceland, are also considered for comparison.

One of the original elements of this work is the use of DPX data to investigate the role of the radar polarimetry experimentally for quantitative estimation of ash plume properties from explosive eruptions. The description on the data processing flow involved in the radar-derived products is given, and the final results are discussed in detail showing how turbulence effects from explosive eruptions might be responsible for the corruption of some of the radar variables whose interpretation is not always straightforward.

The analysis of the sensitivity of millimetre wavelengths to ash content and spatial distribution is discussed to anticipate the potential that will be available in the future with the launch of the first millimetre wave (frequencies from 183 to $664 \mathrm{GHz}$ ) payload aboard the second generation of European polar-orbiting satellites.

The paper is organized into five sections. Section 2 describes the characteristics of the sensors and the definition of measured quantities used here. Section 3 gives the interpretation of the measured quantities for the case study under analysis. Section 4 shows the results of the multi-sensor quantitative estimates of ash and the comparisons between DPX, SPC and SSMIS retrievals. Section 5 provides the summary and final remarks.

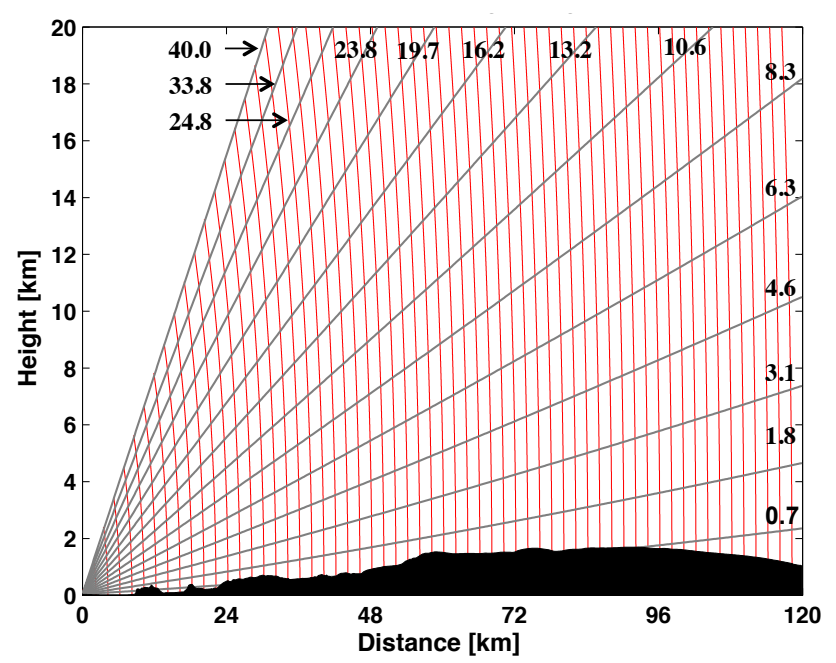

Fig. 1. Radar scan strategy in terms of range-height plot adopted for the mobile X-band radar located at the Iceland site. The antenna elevation angles [deg] are shown close to each theoretical radar ray paths (grey lines). For sake of clarity the radar range gate sizes are shown every $2 \mathrm{~km}$ by red lines instead of the original resolution of $0.25 \mathrm{~km}$. The terrain elevation profile along the direction of $21 \mathrm{deg}$ clockwise from the north is also displayed in black. The radar is positioned at the origin of the axes, and the Grímsvötn caldera is at approximately $70 \mathrm{~km}$ away form the radar.

\section{Data description}

In the following subsections the radar and radiometric variables from DPX and SSMIS are introduced, and the characteristics of both sensors are given. Although dual polarization observations are fairly consolidated for meteorological studies, they are relatively new for ash volcanic applications. Thus, some basic details of the polarimetric radar variables are given hereafter.

\subsection{Ground-based X-band radar measurements}

The DPX sensor is a mobile compact weather radar that is relatively easy to move to the desired locations in case of an ongoing eruption, due to its deployment on a trailer. For the event of 22 May 2011, it has been positioned in the Kirkjubæjarklaustur, southern Iceland, at approximately $70 \mathrm{~km}$ away from the Grímsvötn volcano (Petersen et al., 2012). The list of the main technical specifications of DPX is in Table 1. The representation of the theoretical radar ray paths in a range-height reference system is shown in Fig. 1 for the elevation angles scanned by the radar antenna. A standard atmosphere is assumed to compute the radar ray paths. The DPX data we used have a range and azimuth resolutions of $0.20 \mathrm{~km}$ and $1 \mathrm{deg}$, respectively. The observation geometry is such that the DPX sampling volume over the volcano position (i.e. approximately $70 \mathrm{~km}$ away from the radar site) is approximately $0.59 \mathrm{~km}^{3}$. 


\subsubsection{Polarimetric radar observables}

Being a dual polarization system, DPX transmits and receives electromagnetic energy in two orthogonal polarization states: the horizontal $(\mathrm{H})$ and the vertical $(\mathrm{V})$ one. The variables obtained from DPX are the radar reflectivity factors $\left(Z_{\mathrm{VV}}\right.$ and $\left.Z_{\mathrm{HH}}\right)$ in $\mathrm{dBZ}$, the differential reflectivity $\left(Z_{\mathrm{DR}}\right)$ in $\mathrm{dB}$, the correlation coefficient $\left(\rho_{\mathrm{HV}}\right)$ and the specific differential phase shift $\left(K_{\mathrm{DP}}\right)$ in ${ }^{\circ} \mathrm{km}^{-1}$. They are defined as follows (e.g. Bringi and Chandrasekar, 2001; Marzano et al., 2012a):

$$
\begin{aligned}
Z_{\mathrm{XX}} & =10 \log _{10}\left(\frac{4 \pi \lambda^{4}}{\pi^{5}}<N\left(D_{\mathrm{e}}\right) \cdot\left|\mathbf{S}_{\mathrm{XX}}^{(\mathrm{b})}\left(D_{\mathrm{e}}, \varphi\right)\right|^{2}>\right), \\
Z_{\mathrm{DR}} & =Z_{\mathrm{HH}}-Z_{\mathrm{VV}}, \\
\rho_{\mathrm{HV}} & =\frac{<\mathbf{S}_{\mathrm{HH}}^{(\mathrm{b})}\left(D_{\mathrm{e}}, \varphi\right) \mathbf{S}_{\mathrm{VV}}^{(* \mathrm{~b})}\left(D_{\mathrm{e}}, \varphi\right)>}{\sqrt{<\left|\mathbf{S}_{\mathrm{HH}}^{(\mathrm{b})}\left(D_{\mathrm{e}}, \varphi\right)\right|^{2}><\left|\mathbf{S}_{\mathrm{VV}}^{(\mathrm{b})}\left(D_{\mathrm{e}}, \varphi\right)\right|^{2}>}}, \\
K_{\mathrm{DP}} & =4 \pi \lambda \operatorname{Re}\left[<N\left(D_{\mathrm{e}}\right) \cdot \mathbf{S}_{\mathrm{HH}}^{(\mathrm{f})}\left(D_{\mathrm{e}}, \varphi\right)>\right. \\
& \left.-<N\left(D_{\mathrm{e}}\right) \cdot \mathbf{S}_{\mathrm{VV}}^{(\mathrm{f})}\left(D_{\mathrm{e}}, \varphi\right)>\right] .
\end{aligned}
$$

In Eq. (1) the double subscript XX stands for either $\mathrm{HH}$ or VV indicating the received (first index) and transmitted (second index) polarization. The quantities $\lambda, S_{\mathrm{XX}}, D_{\mathrm{e}}$ and $\phi$ in Eqs. (1)-(4) are the radar wavelength, the complex scattering matrix, the particle spherical volume-equivalent diameter and the canting angle, which is defined in the plane of polarization of the incident wave with respect to its vertical polarization unit vector, respectively. The angle brackets stand for integral over the particle size distribution $(N)$ and the particle orientations within the radar sampling volume. The subscript "b" or "f" of the scattering matrix $\mathbf{S}$ indicates its diffusion components in the backscatter or forward radial directions, respectively.

High values of $Z_{\mathrm{HH}}$ indicate the presence of large particles (compared with the radar wavelength) or a large number of particles with smaller size within a sampling volume. The dynamic range of $Z_{\mathrm{HH}}$ at $\mathrm{X}$-band is approximately from -20 to $60 \mathrm{dBZ}$. $Z_{\mathrm{DR}}$ is a good indicator of the mean drop size and shape of the particles within the sampling volume. Values of $Z_{\mathrm{DR}}$ close to zero indicate spherical particles (e.g. small hail and drizzle or tumbling large hail for meteo-target or randomly oriented oblate/prolate ash particles), whereas positive and negative values indicate horizontally (e.g. rain, melting hail for meteo-target) and vertically oriented particles (e.g. some kind of ice crystals), respectively. The discrimination between prolate and oblate ash particles, to our knowledge, does not lead to a specific ash category. However, the discrimination between spherical and non-spherical fine and coarse ash particles is of interest due to the different settling velocity that these particles have (Riley et al., 2003). The typical dynamical range of $Z_{\mathrm{DR}}$ is between -2 and $5 \mathrm{~dB}$, but, for ash, simulations indicate that values larger than $3 \mathrm{~dB}$ are unlikely to occur. The correlation coefficient, $\rho_{\mathrm{HV}}$, measures the consistency of the returned signal in the $\mathrm{H}$ and $\mathrm{V}$ polarizations in terms of signal power and phase for each received pulse. Being a correlation coefficient, $\rho_{\mathrm{HV}}$ varies between 0 and 1 , and it is an indicator of the complexity of the scattering effects: $\rho_{\mathrm{HV}}$ values close to unity are usually representative of rain or snow; values approximately close to 0.9 are instead associated with hail or wet aggregates; values less than 0.9 are usually associated with non-meteorological targets or with a mixture of different particles within the same radar sampling volume. For ash, low $\rho_{\mathrm{HV}}$ (let us say lower than 0.80) might imply a lot of diversity within the radar sampling volumes possibly caused by turbulence effects. On the other hand, a high $\rho_{\mathrm{HV}}(>0.97)$ tells us that the ash particles within the radar sampling volumes are very uniform in size and shape, and, as a consequence, this might indicate negligible turbulence effects.

The difference between the $\mathrm{H}$ and $\mathrm{V}$ phase shifts is referred to as the differential phase shift $\left(\phi_{\mathrm{DP}}\right)$. Typically, meteorological targets do not show equal shifting in the phase of the received signal at $\mathrm{H}$ and $\mathrm{V}$ polarization states. This is due to target shape and its concentration. The range derivative of the differential phase shift is the specific differential phase $K_{\mathrm{DP}}$. Like $Z_{\mathrm{DR}}, K_{\mathrm{DP}}$ is sensitive to the mean size and shape of the dominant particle within the sampling volume. Indeed, $K_{\mathrm{DP}}$ is sensitive to particle concentration as well. The more particles there are in the sampling volume, the more effects that will occur on $K_{\mathrm{DP}}$. $K_{\mathrm{DP}}$ variations depend on the radar wavelength. At X-band, variations of $K_{\mathrm{DP}}$ can exceed $30^{\circ} \mathrm{km}^{-1}$ in heavy rain while they drop to $-2^{\circ} \mathrm{km}^{-1}$ in vertically aligned ice crystals. For ash, maximum variations of $K_{\mathrm{DP}}$ can be in principle in the range [-30, 140] deg km $\mathrm{km}^{-1}$, in case of intense concentration of the order of $5 \mathrm{~g} \mathrm{~m}^{-3}$ on average. Negative and positive values can be registered for prolate- and oblate-oriented particles, respectively. Randomly oriented ash particles produce lower $K_{\mathrm{DP}}$, which can vary within $[-10,10] \operatorname{deg} \mathrm{km}^{-1}$.

\subsubsection{Polarimetric radar data processing}

The radar data processing can benefit from the experience matured for the observations of weather phenomena, such as clouds and precipitation. The radar signals are processed following several steps as described hereafter. It has to be noted that the radar variables used for this work and described by Eqs. (1)-(4) result from the integration of 23 sampled pulses (SPs) as listed in Table 1. This leads to an integration time of $41.8 \mathrm{~ms}$ (= SP/PRF).

The first step of the radar processing chain is the compensation of the radar reflectivity from the partial beam blocking (PBB) from fixed targets (Doviak and Zrnic, 1993). The PBB map represents the occultation degree at a specific antenna elevation of the radar rays. The positions where the terrain heights intercept the radar sampling volumes are marked with values from 0 to 1 depending on the degree of 

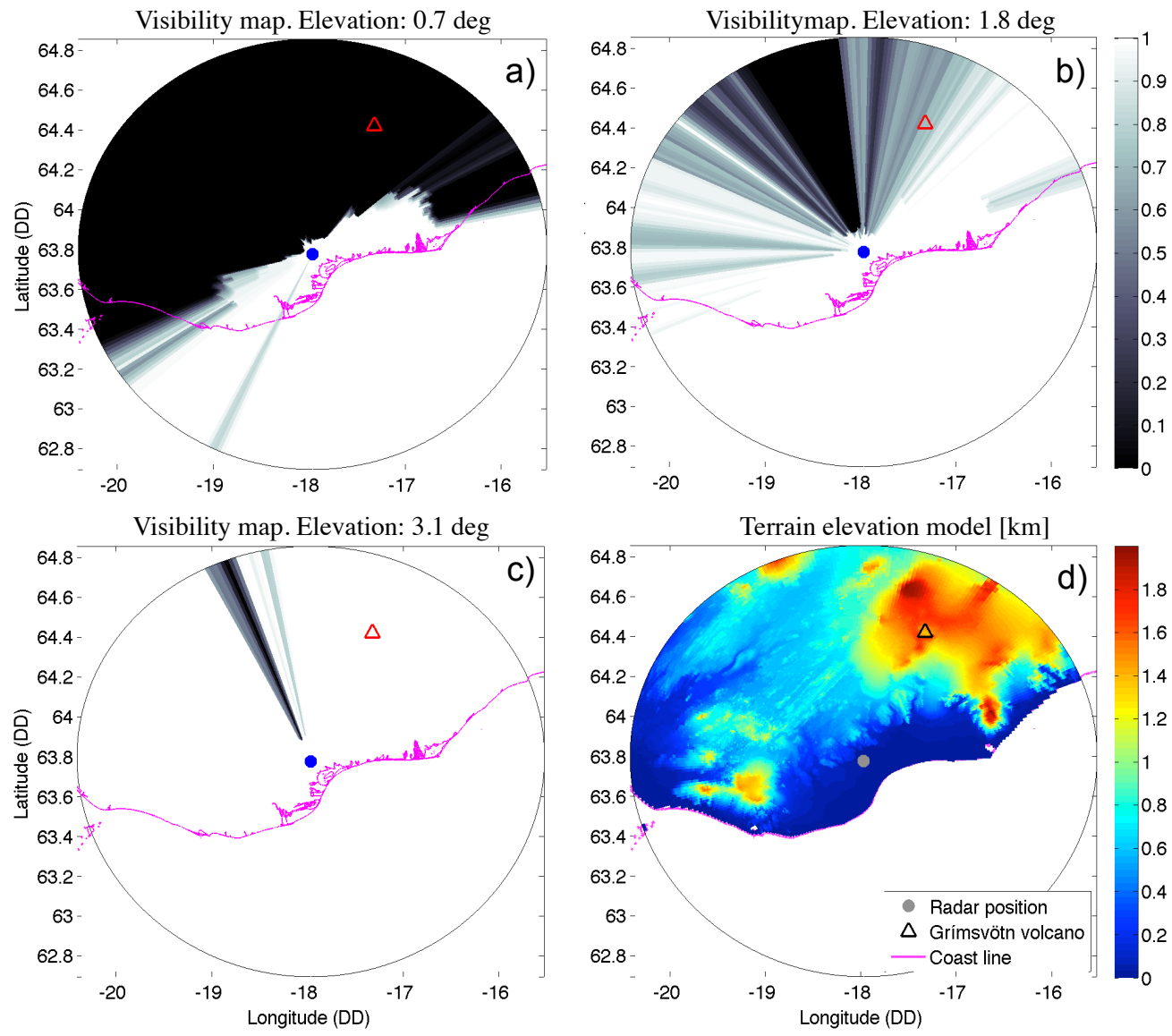

Fig. 2. Visibility maps at three elevations angles [deg]: 0.7 (a), 1.8 (b) and 3.1 (c) for the Iceland DPX radar site. Dark and bright patches show areas where the radar signal is obstructed (visibility $=0$ ) or free from obstacles (visibility $=1$ ) caused by the orography. The terrain elevation model in kilometres, sampled into the polar coordinates radar reference system, is shown in (d) for comparison.

occultation of the radar rays $(\mathrm{PBB}=0$ indicates no radar ray path blockage; $\mathrm{PBB}=1$ indicates $100 \%$ of radar ray path blockage). PBB is obtained from the visibility map as its complementary to the unity. The PBB map is used to compensate, up to $70 \%$, the radar reflectivity using the simplified obstruction function proposed by Bech et al. (2003).

To build the theoretical visibility map, an electromagnetic propagation model is used together with the terrain elevation model (TEM). In this case, the radar signal is assumed to propagate in the standard atmosphere (Doviak and Zrnic, 1993). An empirical approach is also used to define an experimental visibility map. The latter is obtained considering 344 radar acquisitions of reflectivity, which include heterogeneous sky conditions (precipitation, clear air, ash), then normalizing the average reflectivity in the range $[0,1]$. The visibility map used for the PBB compensation is obtained taking the maximum value, for each radar sampling volume, between the theoretical and experimental version of the visibility map. Figure 2 shows the PBB map for the first three elevation angles reported in Fig. 1 as well as the TEM map for comparison.
In the second step, the radar echoes generated by ground clutters are filtered out applying a threshold on the quality map $(Q) . Q$ is generated following the methodology suggested in Vulpiani et al. (2012), and it is obtained weighting, with given membership functions, the clutter map (CM) and the textures of $Z_{\mathrm{DR}}, \rho_{\mathrm{HV}}$ and filtered $\phi_{\mathrm{DP}}$. $\mathrm{CM}$ is obtained in a similar way to PBB as a combination of a theoretical and experimental clutter map. In this case the experimental clutter map is obtained considering only the acquisitions in clear sky conditions (i.e. a subset of the 344 acquisition mentioned before) to identify the radar signals due to nonmeteorological targets better.

In the third step we discarded the radar sampling volumes having a signal-to-noise ratio in $\mathrm{dB}(\mathrm{SNRdB})$ smaller than or equal to 5 decibels $(\mathrm{dB})$. SNR is calculated as

$\mathrm{SNRdB}=C_{\mathrm{SNRdB}}+Z_{\mathrm{HH}}-20 \log _{10}(r)$,

where $C_{\mathrm{SNRdB}}$ is a constant (in $\mathrm{dB}$ ) and $r$ is the range distance from the radar position (in $\mathrm{km}$ ) of a given sample volume. Equation (5) is obtained considering the ratio of the radarreceived power as well as the noise power: $P_{\mathrm{r}}=C_{\mathrm{rad}} Z_{\mathrm{HH}} r^{-2}$ 
and $P_{n}=k T_{0}(F-1) B$ respectively, with $C_{\text {rad }}, k, T_{0}, F$ and $B$ the radar constant, the Boltzmann constant, the ambient temperature, the radar receiver figure noise and the equivalent radar receiver band width. $C_{\mathrm{SNRdB}}$ in Eq. (5) is then defined as $10 \log _{10}\left(C_{\mathrm{rad}} P_{n}^{-1}\right)$.

The constant $C_{\mathrm{SNR}}$ is found using the correlation coefficient, $\rho_{\mathrm{HV}} . \rho_{\mathrm{HV}}$ in the presence of additive noise depends on SNR through the following relation (Bringi and Chandrasekar, 2001):

$\rho_{\mathrm{HV}}=\rho_{\mathrm{HV}}^{n}\left(1+10^{-0.1 \mathrm{SNRdB}}\right)$,

where the apex " $n$ " indicates a noisy quantity. Equation (6) is derived using few mathematical manipulations and the definition of correlation coefficient for a signal added to noise $(s+n)$. The correlation of such a signal is $\rho^{n}(l)=$ $R^{s+n}(l) / R^{s+n}(0)$, where $R$ is the autocorrelation function at time lag $(l)$ and the additive noise is assumed to be white so that $R^{n}(l) \neq 0$ only for $l=0$. In this context the SNR is conveniently defined as $R^{\mathrm{s}}(0) / R^{n}(0)$. The optimal $C_{\mathrm{SNRdB}}$ in Eq. (5) is found when $\rho_{\mathrm{HV}}$ is independent of SNRdB for its values greater than $5 \mathrm{~dB}$. The value of $C_{\mathrm{SNRdB}}$ we found for the DPX radar is $40 \mathrm{~dB}$. Equation (6) is also used to correct $\rho_{\mathrm{HV}}$ for noise effects. $\rho_{\mathrm{HV}}$ can be also affected, more than the other variables, by the non-uniform beam-filling (NUBF) effect. As a general rule the NUBF is more pronounced far away from the radar when the sampling volumes become large enough to include different species of reflecting particles or when the sampling volumes are not completely filled by the reflecting particles. Following the work of Ryzhkov (2007), we compensated $\rho_{\mathrm{HV}}$ from these effects quantifying its average multiplicative bias due to NUBF using the spatial variations of the unfiltered differential phase along the azimuth and elevation directions. Then, we multiplied the bias for $\rho_{\mathrm{HV}}$ in Eq. (6). This procedure only partially compensates for NUBF given the impossibility of resolving scales lower than the available radar spatial resolution.

In the fourth step, filtered $\phi_{\mathrm{DP}}$ and the specific differential phase $K_{\mathrm{DP}}$ are obtained applying a procedure, derived from the retrieval scheme proposed for hydrometeors by Vulpiani et al. (2012), and then tuned for ash targets. The method is iterative, and it automatically removes spikes, offset and wrapped values in $\phi_{\mathrm{DP}}$. With respect to meteorological rain targets, negatives values of $K_{\mathrm{DP}}$ are not filtered out for ash targets. A pre-filter on $\phi_{\mathrm{DP}}$ followed by an additional filter to estimate $K_{\mathrm{DP}}$ is applied. Both filters are convolutional filters, which use a triangular shaped window of width of $5 \mathrm{~km}$. The window width is fixed after checking the correlation of $Z_{\mathrm{HH}}$ vs. $K_{\mathrm{DP}}$. It has been found that a window width of $5 \mathrm{~km}$ gives a correlation of $Z_{\mathrm{HH}}$ vs. $K_{\mathrm{DP}}$ equal to 0.41 , and it is a good compromise between $K_{\mathrm{DP}}$ representativeness and its self-consistency with $Z_{\mathrm{HH}}$ among other choices of the window width.
The last step concerns the calibration of $Z_{\mathrm{DR}}$. As discussed later, given the uncertainty that affects the calibration of $Z_{\mathrm{DR}}$, we decided not to use it for quantitative analyses. However, efforts to process this quantity are accomplished. Operational $Z_{\mathrm{DR}}$ calibration is a challenging process, more complex than compensating $Z_{\mathrm{HH}}$ from the partial beam blocking or estimating $K_{\mathrm{DP}}$ because both the $\mathrm{H}$ and $\mathrm{V}$ channels should be calibrated separately. The goal of $Z_{\mathrm{DR}}$ calibration is to provide an accuracy of at least of $\pm 0.2 \mathrm{~dB}$ of the true value of $Z_{\mathrm{DR}}$. One of the common methods for $Z_{\mathrm{DR}}$ calibration is to consider an external target assumed as a reference with a known $Z_{\mathrm{DR}}$ value (Gorgucci et al., 1999). Usually water clouds in light rain conditions, observed along the zenith direction, should produce $Z_{\mathrm{DR}}=0$ due to the spherical shape of the precipitating small water particles. Deviations of $Z_{\mathrm{DR}}$ from zero, in the condition just described, provide an estimate of the bias of $Z_{\mathrm{DR}}$. Unfortunately, as evidenced by the scan strategy in Fig. 1, 90 deg elevations (looking at the zenith) are not present in the data, making it very difficult to calibrate $Z_{\mathrm{DR}}$. On the other hand, rain precipitation is not likely to be present at the heights sampled by the DPX radar in Iceland. For this reason we sampled radar variables in areas likely to be affected by ice where the expected average $Z_{\mathrm{DR}}$ is known by model simulations (Marzano et al., 2010). Radar returns due to ice are identified selecting sample volumes where $K_{\mathrm{DP}}$ is within the range [0, 2], $\rho_{\mathrm{HV}}$ within [0.91, 0.99], $Z_{\mathrm{HH}}$ within [10, 25], $\mathrm{SNR}_{\mathrm{dB}}$ larger than 42 and height of sample volumes within $[1.2,3.5] \mathrm{km}$. The calibration procedure of $Z_{\mathrm{DR}}$ that we applied leads to a bias of $0.74 \mathrm{~dB}$ that is added to the raw values of $Z_{\mathrm{DR}}$. Additionally, a convolutional filter with a moving triangular window of $5 \mathrm{~km}$ length is applied along each radial direction to filter out noise from $Z_{\mathrm{DR}}$. The data processing we applied did not include any attenuation correction scheme. This is due to the fact that model simulations of prolate and oblate particles give maximum specific attenuations of the order of $0.025,0.030,0.075$ and $0.8\left[\mathrm{~dB} \mathrm{~km}^{-1}\right]$ for fine ash, coarse ash, small lapilli and large lapilli for $K_{\mathrm{DP}}$ lower than $3 \mathrm{deg} \mathrm{km}^{-1}$, as found in the data that we analysed in this work. In addition, as it will be shown later, large lapilli are detected in a small quantity, and the implementation of an attenuation compensation scheme would not produce, in our case, any substantial improvement.

\subsection{Spaceborne microwave radiometer measurements}

The SSMIS radiometer flies aboard the LEO DMSP platforms orbiting at $833 \mathrm{~km}$ height above ground (Yan and Weng, 2008; Kramer, 2002). SSMIS is a conically scanning passive microwave radiometer with several channels in the 19 to $189 \mathrm{GHz}$ range and a swath of approximately $1700 \mathrm{~km}$. The observation angle between the nadir direction and the antenna pointing direction is 45 degrees. SSMIS measures the spectral radiances from the observed scene. The spectral radiance is usually described in terms of brightness temperature (BT) through Planck's law (Ulaby 

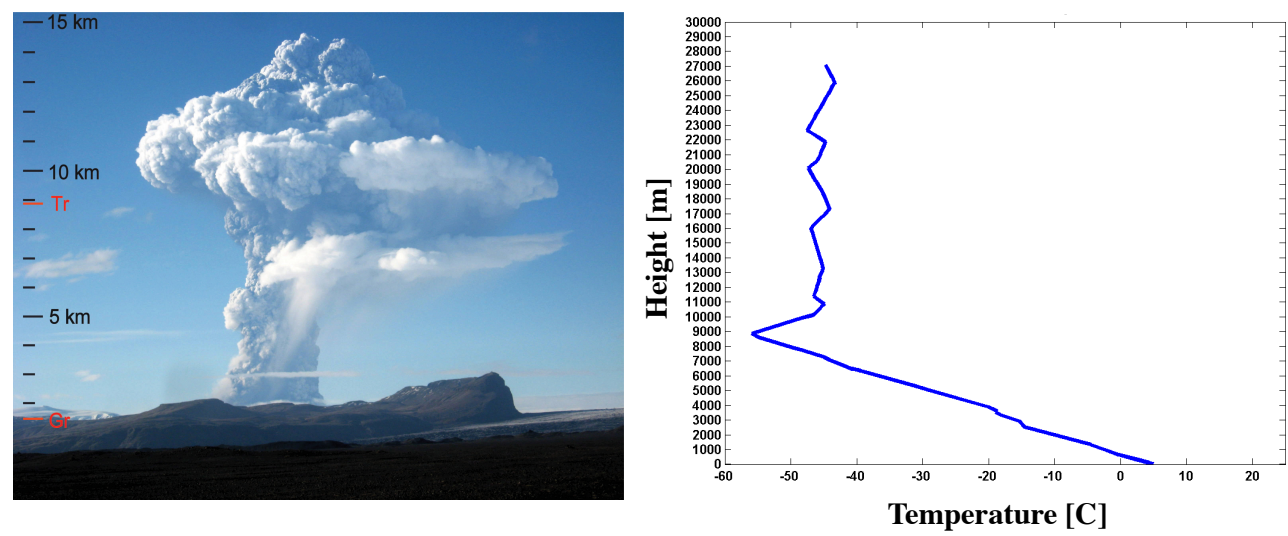

Fig. 3. Left panel: the initial Grímsvötn eruption plume seen from Skeiðarársandur, $50 \mathrm{~km}$ south of the volcano. The left-hand side of the picture reports the scale of altitudes, the ground reference (Gr) at the distance of Grímsvötn and the tropopause level (Tr). Photo by Bolli Valgarðsson, 21 May 2011 at 19:20 UTC (adapted from Petersen et al., 2012). Right panel: radiosounding in Keflavik on 22 May 2011 at 00:00 UTC. The tropopause level is estimated at about $8.9 \mathrm{~km}$.

et al., 1981). BT is frequency and polarization dependent so that both horizontally polarized $\mathrm{BT}_{\mathrm{H}}$ and vertically polarized $\mathrm{BT}_{\mathrm{V}}$ can be available in principle. For the study of ash the SSMIS channels that potentially show an ash signature are those at frequencies and spatial sampling as follows (in GHz/km): $(183 \pm 6) /(12.5),(183 \pm 3) /(12.5)$, $(183 \pm 1) /(12.5),(150.0) /(12.5)$ and $(91.6) /(12.5)$.

BT data are provided as calibrated geo-referenced data for which the antenna pattern effect is already accounted. The geolocation error is estimated as approximately 1 pixel, and thus a pointing refinement may be applied using the coastline reference. When comparing SSMIS-based data with groundbased radar data, a spatial averaging is applied to match the SSMIS pixel with the corresponding set of high-resolution radar sampling bins. Some further descriptions of SSMIS characteristics and data processing for ash cloud observations may be also found in Marzano et al. (2012b).

\section{Data interpretation}

The Grímsvötn volcano, located in the northwest of the Vatnajökull glacier in south-east Iceland, is one of Iceland's most active volcanoes. An explosive subglacial volcanic eruption started in the Grímsvötn caldera in southern Iceland around 19:00 UTC on 21 May 2011. The strength of the eruption decreased rapidly, and the plume was below $\sim 10 \mathrm{~km}$ altitude after $24 \mathrm{~h}$. The eruption was officially declared over on 28 May at 07:00 UTC. More details on the Grímsvötn eruption can be found in Petersen et al. (2012), Marzano et al. (2012b) and Montopoli et al. (2013). An impressive picture of the plume at the beginning of the eruption is shown in Fig. 3. The left-hand side of the picture reports the scale of altitudes, the ground reference ( $\mathrm{Gr}$ ) and the tropopause level ( $\mathrm{Tr})$. $\mathrm{Tr}$ is obtained using the closest radiosounding launched at the Keflavik airport (latitude: $63.96^{\circ}$, longitude: $-22.60^{\circ}$, elevation: $54.0 \mathrm{~m}$ ), which is shown in the right panel. Figure 3 highlights how the plume starts horizontally spreading once it reaches the tropopause.

In the following subsections, we will analyse the instants at 07:10 UTC, 07:12 UTC and 07:15 UTC on 22 May 2011 for SPC, DPX radars and SSMIS radiometer, respectively. This choice is due to the joint availability of these three multiplatform measurements. It is worth mentioning that DPX scaned for several hours on 22 May with a temporal sampling of $10 \mathrm{~min}$. However, the temporal distribution of its measured variables, namely $Z_{\mathrm{HH}}, Z_{\mathrm{DR}}, K_{\mathrm{DP}}$, and $\rho_{\mathrm{HV}}$, within the ash cloud area, is pretty steady with the exception for $Z_{\mathrm{DR}}$, which shows a sporadic positive bias.

\subsection{Radar data interpretation}

A graphical representation of the polarimetric variables defined in Eqs. (1)-(4) is shown in Fig. 4. In this figure, the positions where $Z_{\mathrm{HH}}$ is maximum along each vertical column are identified using all available radar antenna elevations and used to extract the values of the other variables. This procedure ensures a consistent comparison among the radar variables having been extracted at the same positions. In Fig. 4 (top left panel) and Fig. 6, the core of the volcanic plume is well identified by values of $Z_{\mathrm{HH}}$ greater than approximately $25 \mathrm{dBZ}$. Those values spread circularly close to the Grímsvötn caldera. Areas that are far away the caldera show values of $Z_{\mathrm{HH}}$ in the interval $[0,25] \mathrm{dBZ}$. This suggests the presence of small particles in those areas, but it is difficult to discern their nature from $Z_{\mathrm{HH}}$. The variables $K_{\mathrm{DP}}$ and $Z_{\mathrm{DR}}$ (top right and bottom left panel, respectively) do not exhibit a clear pattern for the ash plume as for $Z_{\mathrm{HH}}$. An increase of $K_{\mathrm{DP}}$ and $Z_{\mathrm{DR}}$ around the Grímsvötn plume core is noticed. Their behaviour is analysed in detail later in the paper. The strong depression of $\rho_{\mathrm{HV}}$ values (bottom right panel) seems to be related to the volcanic plume. The reasons 

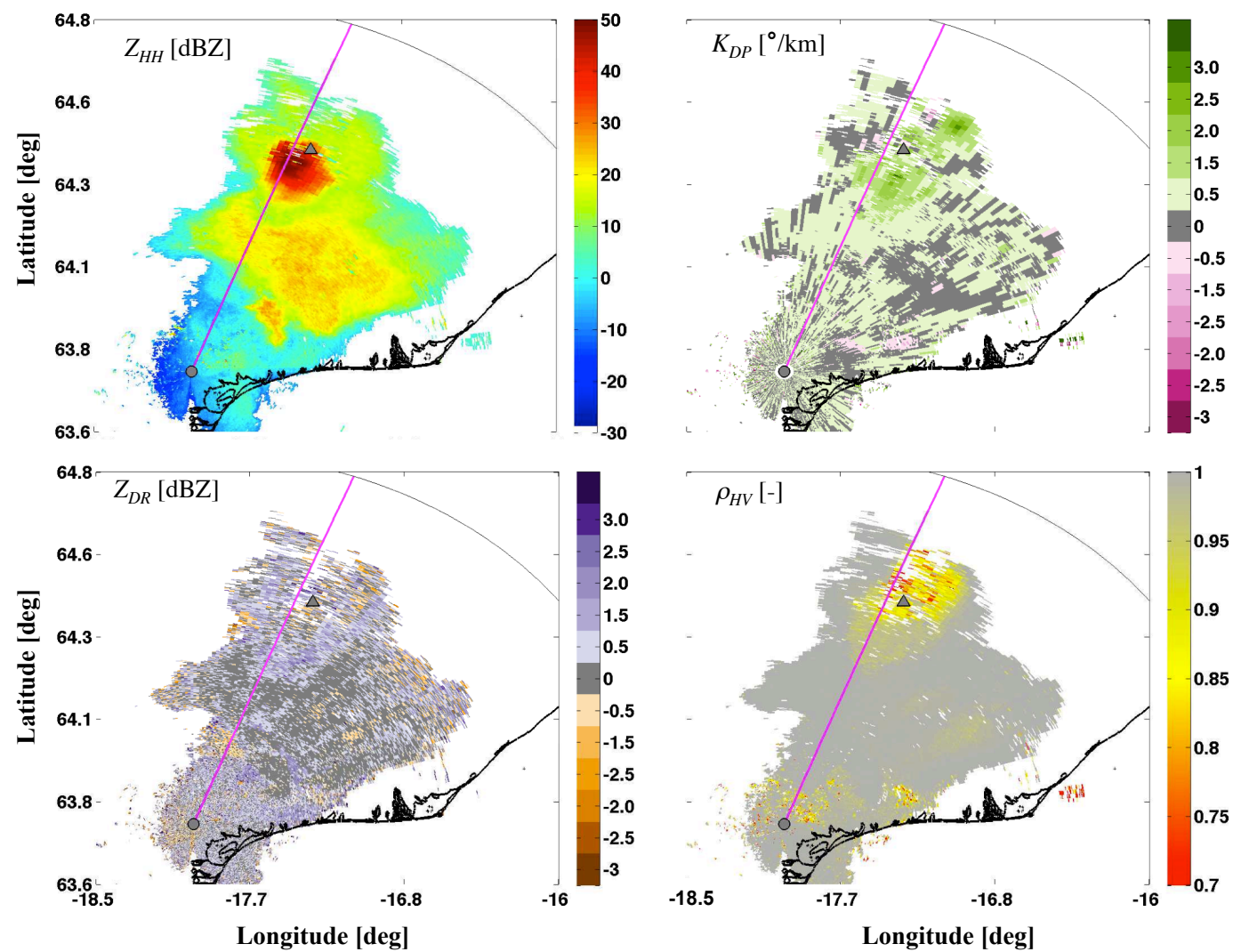

Fig. 4. Vertical maximum intensity of radar variables $Z_{\mathrm{HH}}, K_{\mathrm{DP}}, Z_{\mathrm{DR}}$ and $\rho_{\mathrm{HV}}$ as specified in the top right corner of each panel for the Grímsvötn case study on 22 May 2011, 07:12 UTC. Note the values of all the radar variables here shown are extracted from the positions (range, azimuth, height) where the maximum of the radar reflectivity, $Z_{\mathrm{HH}}$, is registered along each vertical profile. The radar and the volcano vent positions are indicated, in each panel, with the symbols " $O$ " and " $\Delta$ ", respectively. The coastline is in black. The magenta-coloured line shows the azimuth at 21 deg clockwise from the north where the vertical cuts in Fig. 5 are taken.

for this behaviour may be due to the presence of a mixture of non-spherical particles randomly moving and rotating because of turbulence effects. Turbulence effects might be also responsible for the non-uniform filling of radar beams, abbreviated as NUBF, which lead to $\rho_{\mathrm{HV}}$ depression. Even though we compensated $\rho_{\mathrm{HV}}$ for such phenomena (Ryzhkov and Zrnic, 2007), some residual effects can be still present. A slight depression of $\rho_{\mathrm{HV}}$ is also noticed in south-east areas with respect to the volcano position around longitude and latitude of $-16.6^{\circ}$ and $64.1^{\circ}$, respectively. This area is close to the radar position (between 40 and $60 \mathrm{~km}$ ) so that the beam size is small enough to exclude NUBF effects. Incomplete fillings of radar beams are special cases of NUBF, and they may be particularly evident at the ash cloud's edges.

Figure 5 represents the vertical cut of the volcanic plume in terms of the same radar variables discussed before. The vertical cut refers to the direction highlighted with the cyan radial line in Fig. 4, which is the azimuth at $21 \mathrm{deg}$ from the north. Within the plume core, when $Z_{\mathrm{HH}}$ reaches its maximum, $\rho_{\mathrm{HV}}$ starts decreasing, reaching values as low as 0.7 even though, after compensating for NUBF effects on $\rho_{\mathrm{HV}}$, no evident negative correlation has been found with $Z_{\mathrm{HH}}$. Note that residual effects of NUBF might cause the decreasing of $\rho_{\mathrm{HV}}$ at the far side of the plume due to the turbulence effects within the ash cloud. In the same area, $K_{\mathrm{DP}}$ shows positive values within $[0.5,1.0]^{\circ} \mathrm{km}^{-1}$ with a little patch which reaches $1.5^{\circ} \mathrm{km}^{-1}$. Areas outside the core of the plume occasionally show $K_{\mathrm{DP}}$ close to zero. The maximum value registered for $K_{\mathrm{DP}}$ for the analysed case study, within the whole radar volume, is $3^{\circ} \mathrm{km}^{-1}$. A positive correlation of about 0.4 has been found between $K_{\mathrm{DP}}$ and $Z_{\mathrm{HH}}$. The behaviour of $K_{\mathrm{DP}}$ might suggest a different particle orientation inside and outside the plume core. The analysis of $Z_{\mathrm{DR}}$ (bottom left panel) tends to confirm this aspect. Although the calibration of $Z_{\mathrm{DR}}$ is not accurately verified and it cannot be used to make quantitative conclusions, the spatial variability of its values can still provide some information. Values of $Z_{\mathrm{DR}}$ close to zero inside the core of the volcanic plume are quite evident with respect to those outside. Especially in the range distances from 10 to $60 \mathrm{~km}$, the increase of $Z_{\mathrm{DR}}$ close to the ground may suggest the aggregation of small ash particles coated by ice. To support the hypothesis of the presence 

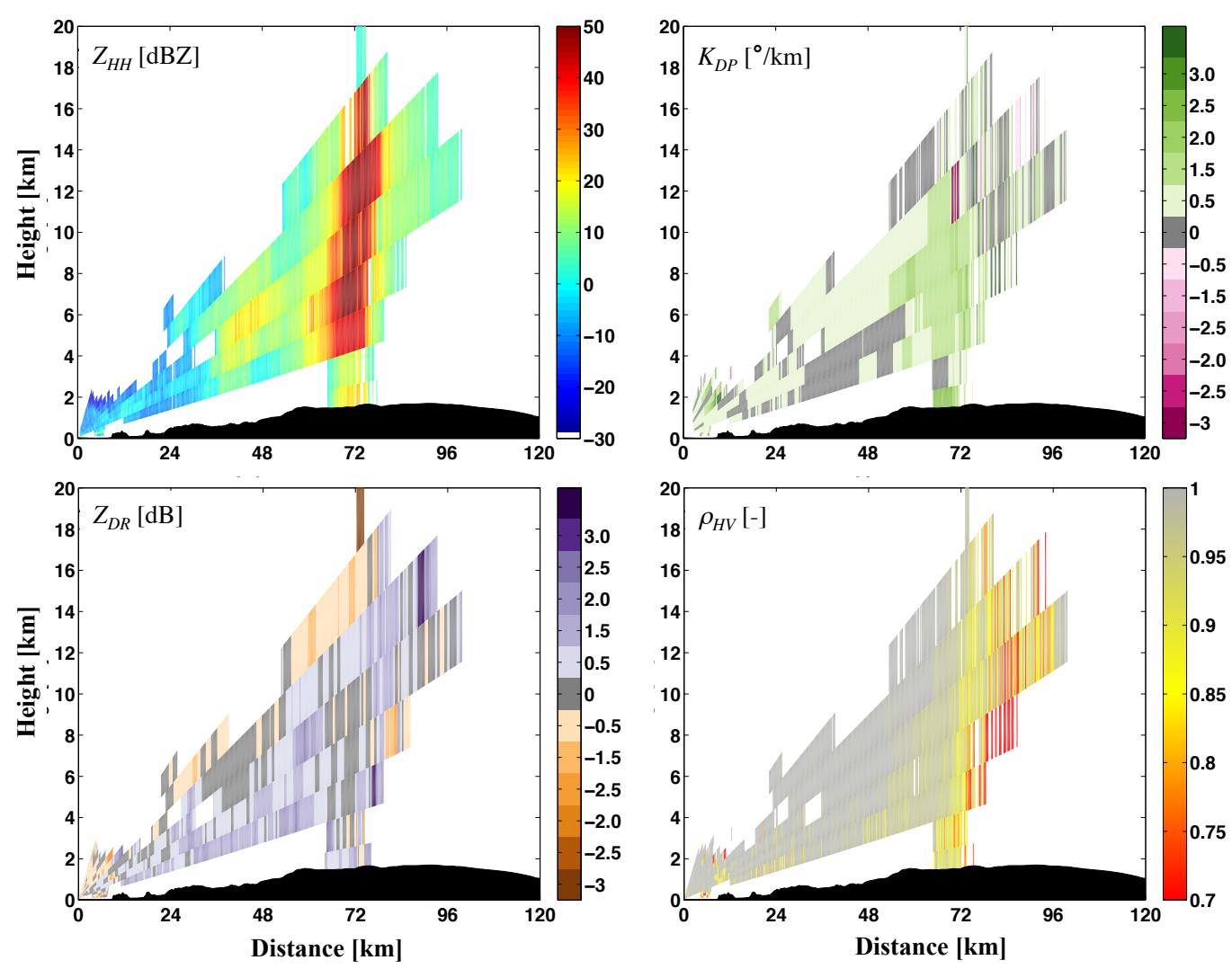

Fig. 5. As in Fig. 4 but in terms of vertical cuts of radar variables along the azimuth at 21 deg clockwise from the north.

of ice in the area of increased $Z_{\mathrm{DR}}$ outside of plume, the radar response model simulations at X-band, as reported in Snyder et al. (2010) and Kaltenboecka and Ryzhkov (2013), show that values of $Z_{\mathrm{HH}}, Z_{\mathrm{DR}}$ and $K_{\mathrm{DP}}$, respectively, of $20 \mathrm{dBZ}$, $0.4 \mathrm{~dB}$ and $0.4^{\circ} \mathrm{km}^{-1}$ at a temperature of $26^{\circ} \mathrm{C}$ can be consistent with small particles of melting hail with equivalent size smaller than $5 \mathrm{~mm}$. It is worth noting that $Z_{\mathrm{DR}}$ may be also corrupted by depolarization effects and differential attenuation due to the presence of ice columns that align under the effect of the atmospheric electrification (Ryzhkov et al., 2007). Depolarization is the transition of power between the two orthogonal polarizations $\mathrm{H}$ and $\mathrm{V}$. In case of depolarization, the interpretation of $Z_{\mathrm{DR}}$ becomes a complex task. In our case, 22 May at 07:12 UTC, $5 l$ lightnings have been registered within the plume core by the World Wide Lightning Location Network (Hutchins et al., 2012). The ice crystal formation is likely at the Iceland latitudes and within the $15 \mathrm{~km}$ height eruption column such as that of the Grímsvötn event analysed here. However, the temporal analysis of the available measurements (not showed) does not evidence a clear correlation between the number of lightnings and the radar polarimetric signatures. It is worth mentioning that depolarization effects might be due also to strong turbulence, which is plausible to occur.
Figure 6 completes the analysis of the radar data set. It shows the range profile of the radar polarimetric variables shown in Fig. 5 along four selected angles of the radar antenna elevation as specified in the title of each panel. The profile of the height of the radar ray paths is also shown by a shaded line. A vertical line marks the position of the Grímsvötn caldera. Note that some of the variables are amplified by a constant factor as specified in the figure legend to appreciate their variations better. $Z_{\mathrm{HH}}$ strongly decreases with distance with respect to its maximum, although the volcanic plume signature is still evident close to the radar position (i.e. approximately $70 \mathrm{~km}$ away from the Grímsvötn caldera). $\rho_{\mathrm{HV}}$ starts decreasing when the maximum of reflectivity is reached, starting to show NUBF effects. In some cases $\rho_{\mathrm{HV}}$ starts to increase again at elevation angles equal to 6.30 deg. Overall, in Fig. 6 a different behaviour of the radar variables is noted between areas inside (in the range $65-75 \mathrm{~km}$ ) and outside the core of the plume.

\subsection{Radiometer data interpretation}

In this section the multi-channel images, acquired by the SSMIS scanning radiometer and collocated in time and space with DPX radar measurements, are analysed in terms of Brightness Temperature at Horizontal polarization $\left(\mathrm{BT}_{\mathrm{H}}\right)$ signatures. Figure 7 shows $\mathrm{BT}_{\mathrm{H}}$ acquired in four channels 

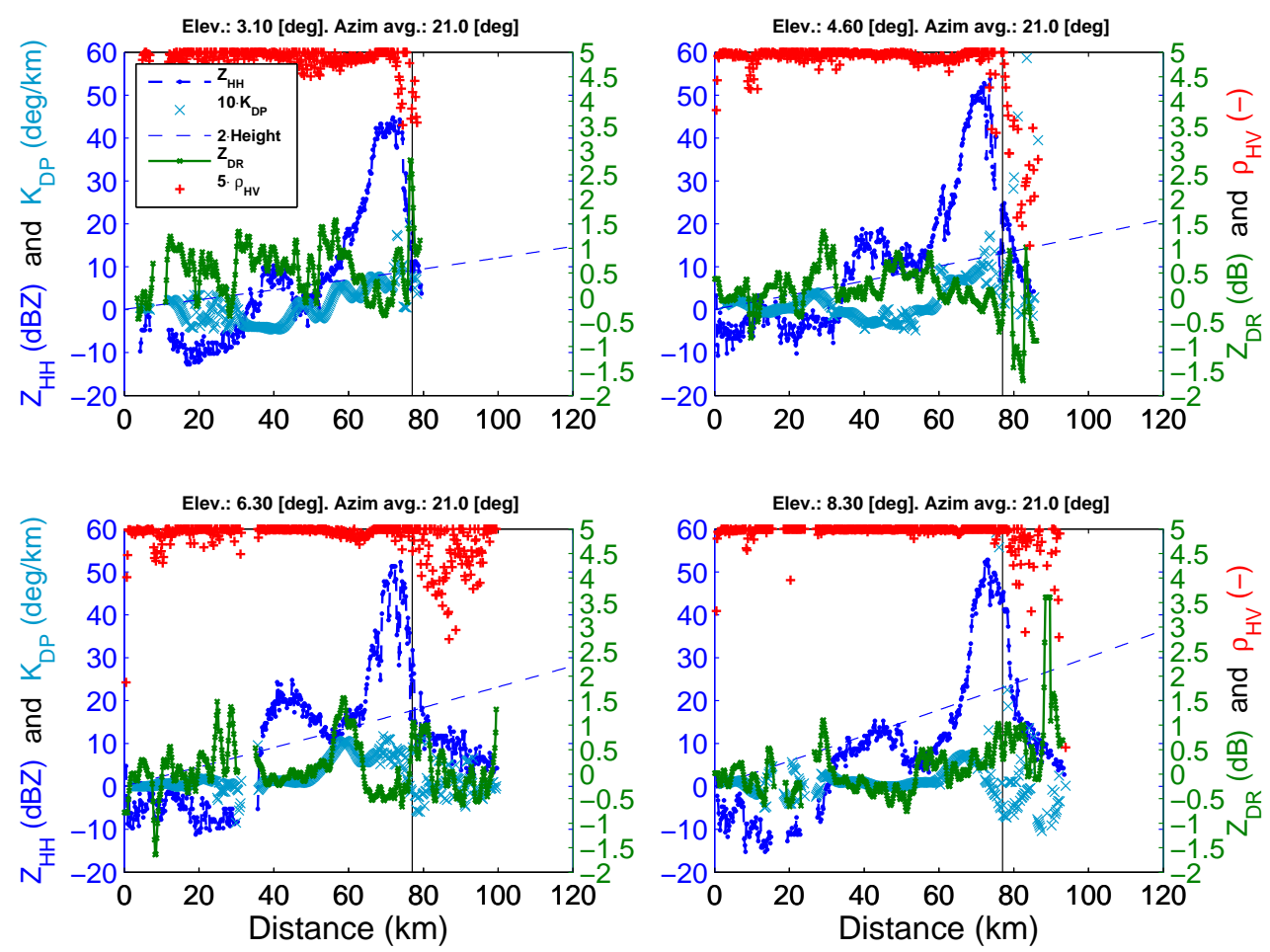

Fig. 6. Range profile of radar variables for four elevations angles as specified in the legend and in the title of each panel, respectively. The azimuth is fixed at $21 \mathrm{deg}$. Profile refers to the DPX radar acquisition at 07:12 UTC on 22 May 2011 at the Grímsvötn site. The vertical grey line indicates the position of the Grímsvötn volcano. The values of $Z_{\mathrm{HH}}$ and $K_{\mathrm{DP}}$ have to be read on the left axes of each panel. Right axes refer to values of $\rho_{\mathrm{HV}}$ and $Z_{\mathrm{DR}}$. The height of the radar ray as a function of distance is also shown by dashed line, and its values are on the left axes. $K_{\mathrm{DP}}$ and $\rho_{\mathrm{HV}}$ and radar ray heights are amplified by a constant factor of 10,5 and 2 , respectively, to appreciate their variations better.

at $150,183 \pm 1,183 \pm 3$ and $183 \pm 6 \mathrm{GHz}$. The depression of $\mathrm{BT}_{\mathrm{H}}$ corresponding to cold temperatures is evident in all SSMIS channels with different intensity. This is most likely a signature of the volcanic plume produced by upwelling microwave radiation that has been emitted from the surface and scattered by ash and ice particles away from the observing directions. The good qualitative correlation between $Z_{\mathrm{HH}}$ contours and the $\mathrm{BT}_{\mathrm{H}}$ depressions supports this fact. The isocontours of $Z_{\mathrm{HH}}$ at 5 and $30 \mathrm{dBZ}$ are superimposed to $\mathrm{BT}_{\mathrm{H}}$ to make the comparisons between the two sources of information easier.

The microwave $\mathrm{BT}_{\mathrm{H}}$ of this scene is clearly frequency dependent and surface dependent. For example, the sea provides a relatively "cold" background at lower frequencies (e.g. at $37 \mathrm{GHz}$, not shown). Above $100 \mathrm{GHz}$, background brightness temperatures increase due to atmospheric water vapour (Wilheit et al., 1994). Below $100 \mathrm{GHz}$, glaciers can provide an ambiguous signature with respect to ash clouds due to the fact that both are relatively efficient scatterers (Grody and Basist, 1996). This spurious radiometric signature of the cloud-free ice cap is detected especially to the north-west of the vent, where no ash plume is present. This is still evident at $150 \mathrm{GHz}$ (top left panel of Fig. 7), where some residual effects of background terrain emissivity are present. Around the strong $183 \mathrm{GHz}$ absorption line, water vapour tends to mask the surface contribution. With increased frequency distance from the water vapour line centre at $183 \mathrm{GHz}$, the contrast between $\mathrm{BT}_{\mathrm{H}}$ from background and those affected by the scattering induced by the volcanic cloud is increased. This is particularly evident comparing $183 \pm 1 \mathrm{GHz}$ with $183 \pm 6 \mathrm{GHz}$, with the latter allowing for an easier identification of the volcanic cloud. The lower atmosphere channels of SSMIS from $22 \mathrm{GHz}$ to $60 \mathrm{GHz}$ were not used here because of their coarse spatial resolution and relatively lower sensitivity to scattering by small particles. Due to similar weighting functions for the two nearly transparent channels at $37 \mathrm{GHz}$ and $50 \mathrm{GHz}$, features are similar, though with the different spatial sampling characteristics mentioned earlier (i.e. $25 \mathrm{~km}$ and $37.5 \mathrm{~km}$ at $37 \mathrm{GHz}$ and $50 \mathrm{GHz}$, respectively). For the channels from $22 \mathrm{GHz}$ to $60 \mathrm{GHz}$, the absorption of oxygen strongly masks the observed scene. 

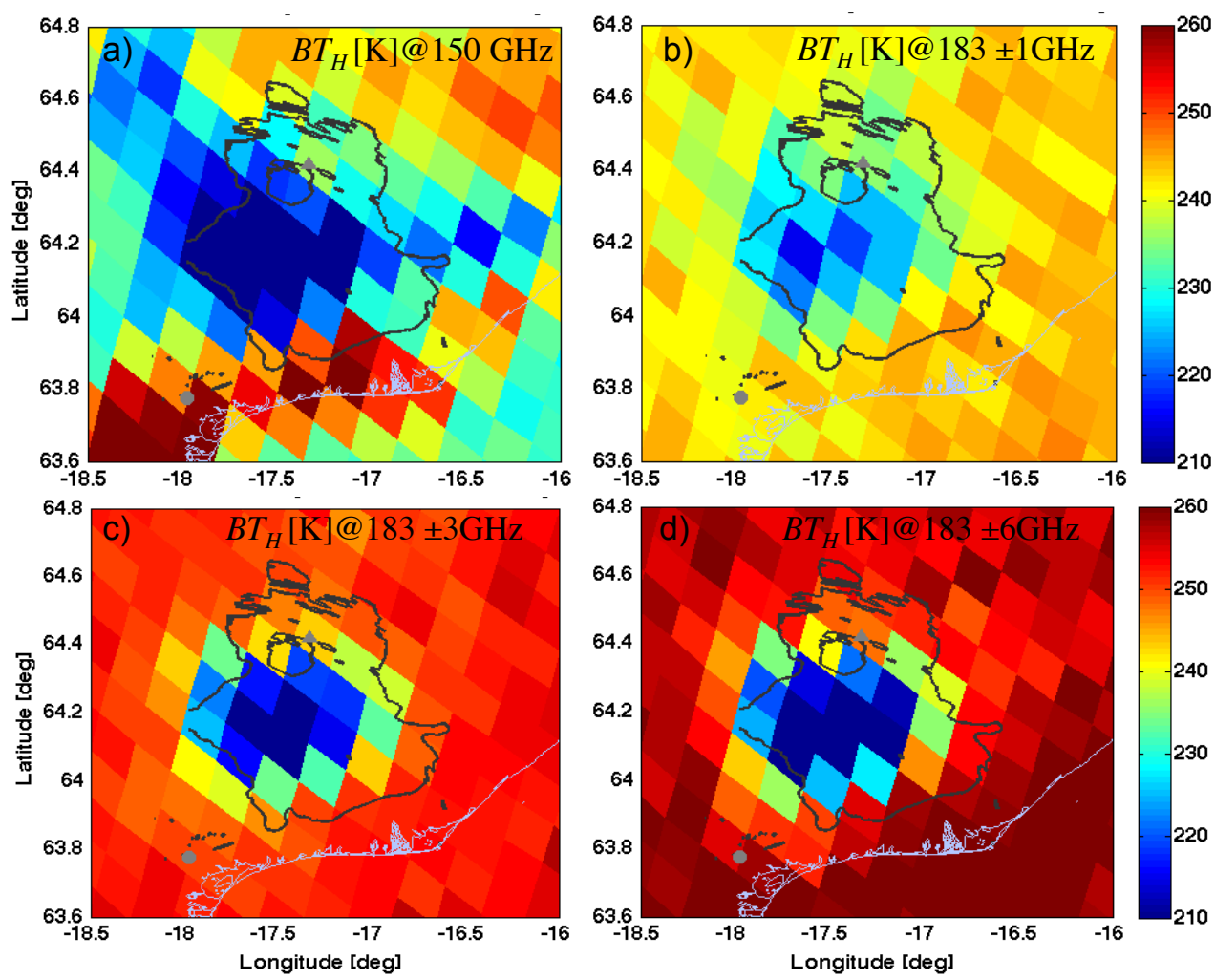

Fig. 7. Maps of brightness temperature at horizontal polarization $\left(\mathrm{BT}_{\mathrm{H}}\right)$ in Kelvin taken from the Special Sensor Microwave Imager/Sounder (SSMIS) carried aboard of the Defense Meteorological Satellite Program (DMSP) F-17. Data were acquired at 07:15 UTC on 22 May 2011 in the surrounding of the Grímsvötn. (a)-(d) show $\mathrm{BT}_{\mathrm{H}} \mathrm{s}$ at 150,183 $\pm 1,183 \pm 3$ and $183 \pm 6 \mathrm{GHz}$, respectively. Contours of the radar reflectivity at 5 and $30 \mathrm{dBZ}$ are shown using black lines. The radar and the volcano vent positions are indicated with the symbols "O" and " $\Delta$ ", respectively. Coast lines are indicated by bright grey lines.

\section{Retrieval results}

To derive quantitative results from the radar data, we applied the volcanic ash radar retrieval for dual-polarization X-band systems (VARR-PX) (Marzano et al., 2006, 2012a).

The VARR aims to provide an automatic ash categorization and ash estimation making use of a synthetic data set of the radar variables generated by a physical-electromagnetic forward model. The synthetic data set allows building relationships between radar variables and physical parameters like ash concentration and ash fallout. The generation of the synthetic data set is obtained by letting the ash particle size distribution parameters and the particle orientation, supposed to be spheroids, to vary in a random way. Additional information like ash particle density, axis ratio, and dielectric constant are set up following values listed in Table II in Marzano et al. (2012a). Automatic discrimination of ash classes with respect to size (fine, coarse, small and lapilli) implies the capability of classifying the radar volume reflectivity measurements into one of the four mentioned classes. Once the ash class is discriminated, then the ash concentration and fallout can be estimated by statistical techniques using the training simulated data sets. Within the VARR technique, the ash classification is performed by the use of maximum a posteriori (MAP probability) estimation. The probability density function (pdf) of each ash class $(c)$, conditioned to the measured radar variables $\boldsymbol{x}_{\mathrm{m}}$, is formulated using Bayes' theorem. The MAP estimation of ash class $c$ corresponds to the maximization with respect to $c$ of the posterior pdf $p\left(c \mid x_{\mathrm{m}}\right)$ under the assumption of multivariate Gaussian pdf's. So far, VARR outputs have been tested with ground data in Marzano et al. (2012b) and compared with satellite data and plume model simulations in Montopoli et al. (2013) providing reasonable results when C-band radar data are used.

The input radar variables that we used in this work for the VARR-PX algorithm for X-band radar are the polarimetric measurements $Z_{\mathrm{HH}}, K_{\mathrm{DP}}$ and $\rho_{\mathrm{HV}}$. VARR-PX, in its general configuration, consists of two main steps:

1. Classification of radar echoes with respect to ash particle size (in $\mathrm{mm}$ ) (fine ash: FA, with average diameters of $0.01 \mathrm{~mm}$; coarse ash: CA with average diameters of $0.1 \mathrm{~mm}$; small lapilli: SL, with average diameters of $1 \mathrm{~mm}$; large lapilli: LL, with average diameters of $10 \mathrm{~mm}$ ) and orientation (prolate: $\mathrm{PO}$, oblate: $\mathrm{OO}$, and tumbling: TO); 
Table 2. Parameters for the ash concentration retrieval $C_{a}=a$. $Z_{\mathrm{HH}}^{b}, C_{a}$ in $\mathrm{g} \mathrm{m}^{-3}, Z_{\mathrm{HH}}$ in $\mathrm{mm}^{6} \mathrm{~m}^{-3}$.

\begin{tabular}{lll}
\hline Ash category & $a$ & $b$ \\
\hline Fine ash & 4.37 & 0.437 \\
Coarse ash & 0.786 & 0.312 \\
Small lapilli & 0.0837 & 0.322 \\
Large lapilli & 0.00193 & 0.472 \\
\hline
\end{tabular}

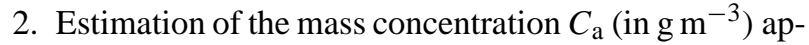
plying a suitable parametric power law (i.e. in the most general case, $C_{\mathrm{a}}=a \cdot Z_{\mathrm{HH}}^{b} \cdot Z_{\mathrm{DR}}^{c} \cdot K_{\mathrm{DP}}^{d}$ ) with estimation parameters (i.e. $a, b, c$ and $d$ ) varying according to the results of the previous classification step.

For the Grímsvötn case study, $Z_{\mathrm{DR}}$ is not considered due to its calibration problems for DPX. For this reason the discrimination of the particle orientation, as foreseen in the full version of VARR-PX, is not performed since it would not be completely reliable. Additionally, the estimate of $C_{a}$, after the classification step, is performed considering only $Z_{\mathrm{HH}}$ (i.e. the parameters $c, d$, are set to zero) because its use produces more robust and reliable results. Note that, even though we estimate the ash concentration for each radar grid point using $C_{a}=a \cdot Z_{\mathrm{HH}}^{b}$, the coefficients " $a$ " and " $b$ " depend on the predominant ash particle category at the considered grid point. This means that " $a$ " and " $b$ " depend on $Z_{\mathrm{HH}}, K_{\mathrm{DP}}$ and $\rho_{\text {HV }}$ which are used as input of the ash category classification scheme. Table 2 lists the values of " $a$ " and " $b$ " that we used in VARR-PX. In order to make the ash classification more reliable, we further modified the original version of VARRPX modifying the "a priory" probability of the ash category LL, so that its occurrence is higher at lower altitudes and vice versa.

Figure 8 shows the vertical profiles of the predominant ash particle category (right panel) and $C_{a}$ (left panel), obtained from VARR-PX outputs. Looking at the ash categories (right panel of Fig. 8), a transition between LL and FA is noted moving from the plume core (distance $=70 \mathrm{~km}$ ) far away toward the radar site (distance $=0 \mathrm{~km}$ ). Some FA is also noted at the flanks of the plume and above a height of $16 \mathrm{~km}$. Within the core of the volcanic plume, LL seems to coexist with SL particles. The mass concentration $C_{a}$ (left panel) is higher on the left flank of the plume, toward the radar site, than within its core. This behaviour seems to be consistent with the SSMIS images in Fig. 7, where the $\mathrm{BT}_{\mathrm{H}}$ depression is more shifted toward the radar site than toward the Grímsvötn caldera. This is an encouraging result on the consistency of the VARR-PX approach. Note that the comparison of the vertical profiles of $C_{a}$ (Fig. 8, left), and those of $Z_{\mathrm{HH}}$ (Fig. 4, upper left), may suggest an unphysical behaviour of $C_{a}$. That is, high values of reflectivity $Z_{\mathrm{HH}}$ above the volcano vent have the biggest particles, but, by far, where smallest particles are detected, the lowest ash mass concentration arises.
Note that $Z_{\mathrm{HH}}$, under the Rayleigh hypothesis, results to be the sixth moment of the particle size distribution so that $Z_{\mathrm{HH}}$ is more sensitive to particle diameter than $C_{a}$. The classification step, used within the algorithm VARR-PX to identify the more probable ash category in radar grid cells, aims to extract the dependence of $C_{a}=a Z_{\mathrm{HH}}^{b}$ on the particle diameters. Thus it may happen that the direct visual inspection between $Z_{\mathrm{HH}}$ and $C_{a}$ estimates is not characterized by a high correlation, but this plot should be looked at together with the one of the ash size class categories (i.e. Fig. 8, right panel). To check the sensitivity of the use of polarimetric variables in the radar retrievals, we tested the case when only $Z_{\mathrm{HH}}$ is used for both classification and estimation steps. In this case the vertical profiles of the ash categories in Fig. 8, right panel, modify, and the class LL is no longer recognized. The presence of LL below $8 \mathrm{~km}$ of altitude, as it results when using $Z_{\mathrm{HH}} K_{\mathrm{DP}}$ and $\rho_{\mathrm{HV}}$, seems to be reasonable for the analysed eruption. In this respect the added value of polarimetry, for the analysed case, is to make the VARR-PX output qualitatively more reliable. Quantitative experimental validations of radar retrievals would require an external reference within the ash cloud in proximity of the volcano vent, which is so far not available to our knowledge.

Similarly to that proposed in Marzano et al. (2013a), Fig. 9 shows a quantitative comparison between SSMIS, DPX and SPC in terms of total columnar concentration (TCC) of $C_{a}$. SPC is the single polarization C-band radar in Keflavik ( $260 \mathrm{~km}$ away from the Grímsvötn caldera, Montopoli et al., 2013). For the comparison of Fig. 9, we used two vertical cuts from SPC and DPX acquired at 07:10 UTC and 07:12 UTC on 22 May 2011 at the azimuth of $81 \mathrm{deg}$ and $21 \mathrm{deg}$ from the north, respectively. In the case of SPC, the version of VARR for single polarization radar systems, VARR-SP, is used considering only $Z_{\mathrm{HH}}$ for both steps of ash classification and estimation of TCC. The quality of the ash retrieval of SPC has been already tested in Marzano et al. (2012b) where comparisons with ground measurements and models outputs are performed. To allow a better evaluation of the results, TCCs are averaged on the same reference grid of SSMIS to match its coarser grid resolution. The SSMIS channel used for the comparison is that at $183 \pm 6 \mathrm{GHz}$. To convert $\mathrm{BT}_{\mathrm{H}}[\mathrm{K}]$ into TCC $\left[\mathrm{kg} \mathrm{m}^{-2}\right]$, an inverse linear relation is applied (Marzano et al., 2013a):

$\mathrm{TCC}=s_{1}+s_{2} \mathrm{BT}_{\mathrm{H}}(183 \pm 6)$,

where $s_{1}$ and $s_{2}$ are the empirically based regression coefficients which are independent of the surface background and the atmospheric scene. The value of these coefficients is $s_{2}=-1.062$ and $s_{1}=262.1$ for DPX and $s_{2}=-2.982$ and $s_{1}=226.8$ for SPC radar.

The results are indicated in panel (a) of Fig. 9. The correlation of the SSMIS $\mathrm{BT}_{\mathrm{H}}$ at $183 \pm 6 \mathrm{GHz}$ and TCC DPX radar retrieval has been found to be -0.67 . Panels (b) and (c) show the maps of TCC $\left[\mathrm{kg} \mathrm{m}^{-2}\right]$ for SSMIS and DPX 

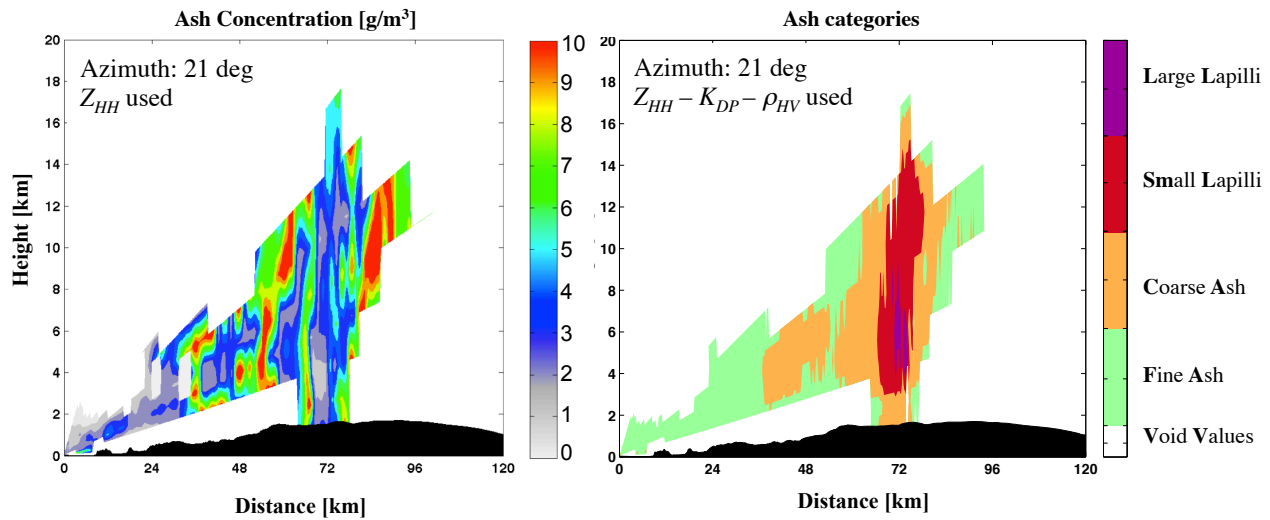

Fig. 8. (Left) ash mass concentration in $\left(\mathrm{g} \mathrm{m}^{-3}\right.$ ) and (right) ash categories from the DPX radar acquisition at the 07:12 UTC on 22 May 2011 at the Grímsvötn site (Iceland). Ash categories are large lapilli, small lapilli, coarse ash and fine ash with average equivalent diameter in millimetres of $10,1,0.1,0.01$, respectively. The ash mass concentration on the left panel is estimated using $C_{a}=a \cdot Z_{\mathrm{HH}}^{b}$ with coefficients " $a$ " and " $b$ ", whose values depend on the ash categories shown on the right panel.
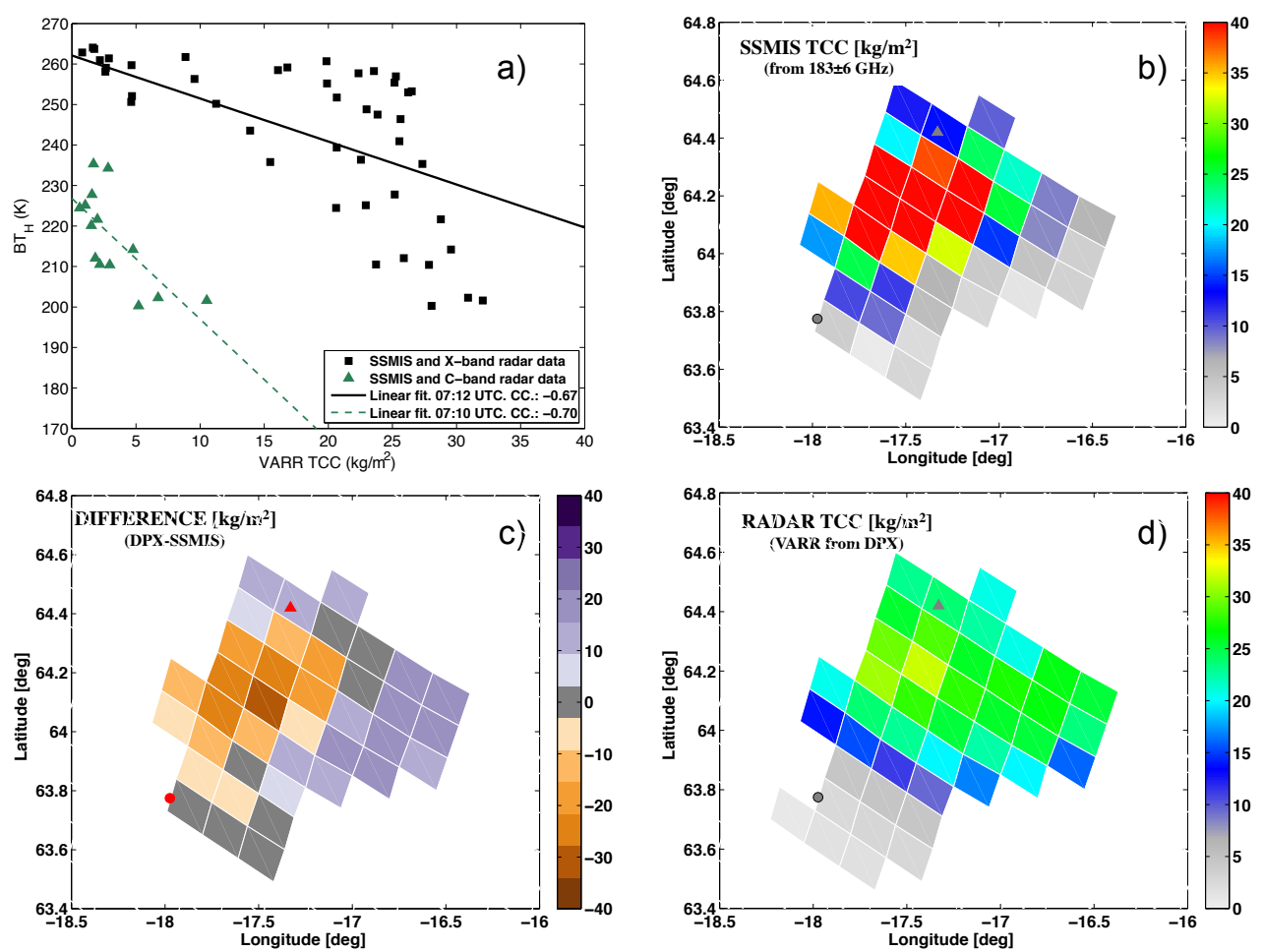

Fig. 9. (a) brightness temperature at horizontal polarization $\left(\mathrm{BT}_{\mathrm{H}}\right)[\mathrm{K}]$ from SSMIS versus the total columnar content (TCC) $\left[\mathrm{kg} \mathrm{m}^{-2}\right]$. TCC is estimated through the volcanic ash radar retrieval (VARR-PX) technique using X-band dual polarization (DPX) and C-band single polarization (SPC) radar. DPX and SPC data are acquired at 07:12 UTC and 07:10 UTC, respectively, on 22 May 2011 at the Grímsvötn site. (b) Retrieval of TCC from SSMIS using the channel at $183 \pm 6 \mathrm{GHz}$ and the linear relation shown by solid red line in (a). (c) Retrieval of TCC from DPX data using the VARR and $Z_{\mathrm{HH}}, K_{\mathrm{DP}}$ and $\rho_{\mathrm{HV}}$ radar variables. (d) Difference map: estimates in (c) minus that in (b).

in the pixels where radar echoes are registered. The agreement between the two estimates is relatively poor. The differences are shown in panel (c) with a relatively low average value of $0.16 \mathrm{~kg} \mathrm{~m}^{-2}$ but positive and negative peaks reaching values up to $\pm 20\left(\mathrm{~kg} \mathrm{~m}^{-2}\right)$. This is probably due to a combination of causes, such as geo-location uncertainty and non-linearity of the $\mathrm{BT}_{\mathrm{H}}-\mathrm{TCC}$ relationship. About the differences between the two radar estimates from DPX and SPC (Fig. 9a), it could be due to three main factors: (i) DPX and SPC are positioned at 70 and $260 \mathrm{~km}$ from the Grímsvötn 
caldera, respectively. This implies that the two radars observe the same scene with different geometry of observation. In particular SPC radar, at a distance of $260 \mathrm{~km}$, partially overshoots the volcano plume, being its lowest height of the ray path approximately $5 \mathrm{~km}$ above the ground. This leads to unavoidable underestimation of columnar integrals; (ii) the transverse section of the sampling volumes of SPC is approximately $4.5 \mathrm{~km}$ (i.e. 2.8 times larger than that of DPX). This means a larger sampling volume of SPC than DPX implying a larger probability to include inhomogeneity in the SPC sampling volumes with respect to DPX. This issue is often referred to as "non-uniform beam filling" as described in Kitchen and Jackson (1993), and it can contribute to smooth down the reflectivity. This is probably the effect that is shown in Fig. 9a; (iii) the retrievals of TCC from DPX and SPC are not consistent with each other,the first one being based on the use of the polarimetric variables while the second uses only $Z_{\mathrm{HH}}$. When DPX estimates are performed using only $Z_{\mathrm{HH}}$ (i.e. made consistent with those derived from SPC), the $\mathrm{BT}_{\mathrm{H}}-\mathrm{TCC}$ relation in Fig. 9 top left panel remains almost unchanged. The distribution of the difference of TCC values (i.e. $\left.\mathrm{TCC}\left(Z_{\mathrm{HH}}\right)-\mathrm{TCC}\left(Z_{\mathrm{HH}}, K_{\mathrm{DP}}, \rho_{\mathrm{HV}}\right)\right)$ ranges over -1 and $0.70 \mathrm{~kg} \mathrm{~m}^{-2}$. Thus, the use of the radar polarimetry has a still appreciable impact on the radar-derived integral columnar content of ash even though this does not sensibly affect the correlation between $\mathrm{TCC}$ and $\mathrm{BT}_{\mathrm{H}}$.

\section{Conclusions}

In this work ground radar and satellite radiometer observations at microwave frequencies are exploited for the study of volcanic eruptions. The case study considered is occurred on 22 May 2011 at the Grímsvötn caldera in Iceland. Radar data have the characteristic to be acquired in the two orthogonal vertical and horizontal polarizations. The main conclusions are as follows:

i. radar acquisition at X-band can clearly detect the volcanic plume and the cloud spreading in the surrounding area of the Grímsvötn, which showed a horizontal extension of approximately $100 \times 130 \mathrm{~km}$;

ii. dual polarization signatures from X-band radar data, DPX, are not easy to interpret. The co-polar reflectivity $Z_{\mathrm{HH}}$ shows values greater than $25 \mathrm{dBZ}$ within the plume core and values around $15 \mathrm{dBZ}$ away from it. The correlation coefficient $\rho_{\mathrm{HV}}$ between the orthogonal polarizations shows an abrupt decrease in the area interested by the core of the volcanic plume. This might be interpreted as a consequence of turbulent effects that facilitate the shuffling of various ash particles causing the decrease of $\rho_{\mathrm{HV}}$. The differential reflectivity $Z_{\mathrm{DR}}$, more than other radar variables, can be affected by factors depending on the radar system (bias) and the observed phenomena (depolarization induced by lightning and/or strong turbulence). This makes its interpretation challenging. Its behaviour for the Grímsvötn case study seems to suggest non-spherical particles at the side of the plume as well as at lower elevations far from the core of the volcanic plume. Within the core of the volcanic plume, lower values of $Z_{\mathrm{DR}}$ are registered, suggesting tumbling or spherical particles; the specific differential phase $K_{\mathrm{DP}}$ shows positive increments within the plume. Additionally, the use of polarimetric variables has shown to provide more reliable qualitative results in terms of ash categories provided by VARR-PX output even though the differences of the quantitative outcomes are minimal when compared with microwave satellite estimates.

iii. the comparison of the total columnar concentration from DPX and brightness temperature at horizontal polarization, $\mathrm{BT}_{\mathrm{H}}$, from the satellite SSMIS radiometer, shows high correlation. The derived $\mathrm{BT}_{\mathrm{H}}-\mathrm{TCC}$ relationship was compared with the analogous relationship derived from the SPC weather radar data for the same case study. The two regressions from DPX and SPC denote some differences, which may be mainly explained by the different spatial resolutions of the two radar systems that might induce more pronounced nonuniform beam-filling effects in the C-band radar measurements than those at X-band.

Future works should be devoted to deepen the analysis of dual-polarization radar data though a systematic analysis of a larger number of case studies in order to consolidate the role of satellite microwave radiometer observations as an ash cloud remote sensing technique.

Acknowledgements. A special thank is due to Paola Pagliara and Bernardo De Bernardinis of the Italian Dept. of Civil Protection (Italy) for supporting the X-band radar operations in Iceland and Sigrún Karlsdóttir and Bolli Palmason of the Iceland Meteorological Office (Iceland) for providing and assisting us in reading the Xband radar data. The authors wish to thank the World Wide Lightning Location Network (http://wwlln.net), a collaboration among over 50 universities and institutions, for providing the lightning location data used in this paper.

Thanks are due to the European Commission (EC) for funding this work under the Marie Curie Fellowship within the call FP7-PEOPLE-2010-IEF, grant number 273666. and through the FP7 project FUTUREVOLC "A European volcanological supersite in Iceland: a monitoring system and network for the future" (grant agreement no. 308377).

Edited by: P. Di Girolamo 


\section{References}

Bech, J., Codina, B., Lorente, J., and Bebbington, D.: The sensitivity of single polarization weather radar beam blockage correction to variability in the vertical refractivity gradient, J. Atmos. Ocean. Technol., 20, 845-855, 2003.

Bringi, V. N. and Chandrasekar, V.: Polarimetric Doppler Weather Radar: Principles and Applications, Cambridge, UK, Cambridge Univ. Press, 2001.

Cadle, R. D., Lazrus, A. L., Huebert, B. J., Heidt, L. E., Rose, W. I., Woods, D. C., Chuan, R. L., Stoiber, R. E., Smith, D. B., and Zielinski, R. A.: Atmospheric implications of studies of Central American volcanic eruption clouds, J. Geophys. Res., 84, 69616968, 1979.

Delene, D. J., Rose, W. I., and Grody, N. C.: Remote sensing of volcanic clouds using special sensor microwave imager data, J. Geophys. Res., 101, 11579-11588, 1996

Denlinger, R., Webley, P., Mastin, L. G., and Schwaiger, H.: A Bayesian Method to Rank Different Model Forecasts of the Same Volcanic Ash Cloud, in: Lagrangian Modeling of the Atmosphere, edited by: Lin, J., Brunner, D., Gerbig, C., Stohl, A., Luhar, A., and Webley, P., Geopress, Washington DC, 299-310, 2013

Doviak, R. J. and Zrnic, D. S.: Doppler Radar and Weather Observations, Academic Press, Cambridge University Press, 562 pp., 1993.

Gorgucci, E., Scarchilli, G., and Chandrasekar, V.: A procedure to calibrate multiparameter weather radar using properties of the rain medium, IEEE Trans. Geosci. Remote Sens., 37, 269-276, 1999.

Grody, N. C. and Basist, A. N.: Global identification of snowcover using SSM/I measurements, IEEE Trans. Geosci. Rem. Sens, 34, 237-249, 1996

Herzog, M. and Graf, H.-F.: Applying the three-dimensional model ATHAM to volcanic plumes: Dynamic of large co-ignimbrite eruptions and associated injection heights for volcanic gases, Geophys. Res. Lett., 37, L19807, doi:10.1029/2010GL044986, 2010.

Hutchins, M.L., Holzworth, R. H., Rodger, C. J., and Brundell, J. B.: Far field power of lightning strokes as measured by the World Wide Lightning Location Network, J. Atmos. Ocean. Tech., 29, 1102-1110, 2012.

Kaltenboecka, R. and Ryzhkov, A.: Comparison of polarimetric signatures of hail at S and C bands for different hail sizes", Atmos. Res., 123, 323-336, 2013.

Kitchen, M. and Jackson, P. M.: Weather radar performance at long range - simulated and observed, J. Appl. Meteor., 32, 975-985, 1993.

Kramer, H. J.: Observation of the Earth and Its Environment: Survey of Missions and Sensors, 4th Edn., Springer, ISBN 3-54042388-5, 2002

Maki, M., Maesaka, T., Kozono, T., Nagai, M., Furukawa, R., Nakada, S., Koshida, T., and Takenaka, H.: Quantitative volcanic ash estimation by operational polarimetric weather radar, Proceedings of the 9th International Symposium on Tropospheric Profiling, L'Aquila, Italy, September 2012, ISBN: 97890-815839-4-7, 2012.

Marzano, F. S., Barbieri, S., Vulpiani, G., and Rose, W. I.: Volcanic ash cloud retrieval by ground-based microwave weather radar, IEEE Trans. Geosci. Remote Sens., 44, 3235-3246, 2006.
Marzano, F. S., Botta, G., and Montopoli, M.: Iterative Bayesian Retrieval of Hydrometeor Content From X-Band Polarimetric Weather Radar, IEEE Trans. Geosci. Rem. Sens., 48, 3059-3074, doi:10.1109/TGRS.2010.2045231, 2010.

Marzano, F. S., Lamantea, M., Montopoli, M., Di Fabio, S., and Picciotti, E.: The Eyjafjöll explosive volcanic eruption from a microwave weather radar perspective, Atmos. Chem. Phys., 11, 9503-9518, doi:10.5194/acp-11-9503-2011, 2011.

Marzano, F. S., Picciotti, E., Vulpiani, G., and Montopoli, M.: Synthetic Signatures of Volcanic Ash Cloud Particles From X-Band Dual-Polarization Radar, IEEE Trans. Geosci. Remote Sens., 50 , 193-211, doi:10.1109/TGRS.2011.2159225, 2012a.

Marzano, F. S., Lamantea, M., Montopoli, M., Oddsson, B., and Gudmundsson, M. T.: Validating sub-glacial volcanic eruption using 784 ground-based C-band radar imagery, IEEE Trans. Geosci. Remote. Sens., 785 1266-1282, 2012b.

Marzano, F. S., Lamantea, M., Montopoli, M., Herzog, M., Graf, H., and Cimini, D.: Microwave remote sensing of the 2011 Plinian eruption of the Grímsvötn Icelandic volcano, Remote Sens. Environ., 129, 168-184, 2013a.

Marzano, F. S., Picciotti, E., Montopoli, M., and Vulpiani, G.: Inside Volcanic Clouds: Remote Sensing of Ash Plumes Using Microwave Weather Radars, Bull. Amer. Meteor. Soc., 94, 15671586, doi:10.1175/BAMS-D-11-00160.1, 2013b.

Mastin, L. G., Guffanti, M., Ewert, J. E., and Spiegel, J.: Preliminary spreadsheet of eruption source parameters for volcanoes of the world: US Geological Survey Open-File Report 20091133, 1.2, 25 pp., available at: http://pubs.usgs.gov/of/2009/ $1133 /, 2009$

Montopoli, M., Cimini, D., Lamantea, M., Herzog, M., Graf, H. F., and Marzano, F. S., , Microwave radiometric remote sensing of volcanic ash clouds from space: model and data analysis, IEEE Trans. Geosci. Remote Sens., 51, 4678-4691, doi:10.1109/TGRS.2013.2260343, 2013.

Newhall, C. G. and Self, S.: The volcanic explosivity index (VEI) an estimate of explosive magnitude for historical volcanism, J. Geophys. Res. Oceans (1978-2012), 87, 1231-1238, 1982.

Petersen, G. N., Bjornsson, H., Arason, P., and von Löwis, S.: Two weather radar time series of the altitude of the volcanic plume during the May 2011 eruption of Grímsvötn, Iceland, Earth Syst. Sci. Data, 4, 121-127, doi:10.5194/essd-4-121-2012, 2012.

Riley, C. M., Rose, W. I., and Bluth, G. J. S.: Quantitative shape measurements of distal volcanic ash, J. Geophys. Res., 108, 2504-2514, 2003.

Rose, W. I., Bluth, G. J. S., and Ernst, G. G. J.: Integrating retrievals of volcanic cloud characteristics from satellite remote sensors A summary, Phil. Trans. R. Soc. A, 358, 1770, 1585-1606, 2000.

Ryzhkov, A.: The Impact of Beam Broadening on the Quality of Radar Polarimetric Data, J. Atmos. Ocean. Tech., 24, 12561267, doi:10.1175/JTECH2003.1, 2007.

Ryzhkov, A. V. and Zrnic, D. S.: Depolarization in Ice Crystals and Its Effect on Radar Polarimetric Measurements, J. Atmos. Ocean. Tech., 24, 1256-1267, doi:10.1175/JTECH2034.1, 2007.

Snyder, J. C., Bluestein, H. B., and Zhang, G.: Attenuation Correction and Hydrometeor Classification of High-Resolution, Xband, Dual-Polarized Mobile Radar Measurements in Severe Convective Storms, J. Atmos. Ocean. Tech., 27, 1979-2001, 2010. 
Sparks, R. S. J.: Forecasting volcanic eruptions, Earth Planet Sci. Lett. Front Earth Sci. Ser., 210, 1-15, 2003.

Ulaby, F. T., Moore, R. K., and Fung, A. K.: Microwave Remote Sensing: Active and Passive, Vol. I. Microwave Remote Sensing Fundamentals and Radiometry, Addison-Wesley, Advanced Book Program, Reading, Massachusetts, 456 pp., 1981.

Vulpiani, G., Montopoli, M., Delli Passeri, L., Gioia, A., Giordano, P., and Marzano, F. S.: On the Use of Dual-Polarized C-Band Radar for Operational Rainfall Retrieval in Mountainous Areas, J. Appl. Meteor. Climatol., 51, 405-425, 2012.

Vulpiani, G., Montopoli, M., Picciotti, E., and Marzano, F. S.: On the use of polarimetric X-band weather radar for volcanic ash clouds monitoring, AMS Radar Conference, Pittsburgh (PAUSA), 2011.
Webley, P., and Mastin, L.: Improved prediction and tracking of volcanic ash clouds Original Research Article, J. Volcanol. Geoth. Res., 186, 1-9, 2009.

Wilheit, T., Adler, R., Avery, S., Barrett, E., Bauer, P., Berg, W., Chang, A., Ferriday, J., Grody, N., Goodman, S., Kidd, C., Kniveton, D., Kummerow, C., Mugnai, A., Olson, W., Petty, G., Shibata, A., and Smith, E. A.: Algorithms for the retrieval of rainfall from passive microwave measurements, Remote Sens. Rev., 11, 163-194, 1994.

Yan, B. and Weng, F.: Intercalibration between special sensor microwave imager/sounder and special sensor microwave imager, IEEE Trans. Geosci. Remote Sens., 46, 984-995, 2008. 